\title{
Ser, Devenir, Subsunción: las raíces Kantianas de una problemática Marxista ${ }^{\mathrm{I}}$
}

\section{Being, Becoming, Subsumption: The Kantian Roots of a Marxist Problematic}

\author{
Andrés Saenz de Sicilia \\ Universidad Nacional Autónoma de México \\ a.e.saenzdesicilia@gmail.com
}

\begin{abstract}
Resumen: Una de las tensiones fundamentales en los escritos de Marx surge de la compleja relación entre los aspectos sistemáticos e históricos de su descripción de la sociedad capitalista. Este artículo argumenta que entre todos los conceptos desplegados por Marx la 'subsunción' es clave con respecto a este tema. Las diferentes formas de subsunción capitalista planteadas por Marx designan los mecanismos por los cuales el capital conforma la dinámica de desarrollo de las sociedades modernas. Sin embargo, el concepto está subteorizado en los escritos de Marx y ha sido objeto de interpretaciones divergentes. Sus implicaciones siguen siendo discutidas. Volviendo a los orígenes filosóficos de la subsunción, en particular a la reconceptualización "crítica" de Kant como un acto productivo de "determinación sintética”, este artículo busca establecer su centralidad para el pensamiento marxista. Se argumenta que la subsunción es la categoría fundamental de análisis que vincula al capital como sistema con el capital como historia.
\end{abstract}

${ }^{1}$ La investigación realizada para este artículo fue apoyada por una beca de investigación posdoctoral otorgada por la DGAPA de la Universidad Nacional Autónoma de México (2020). 
Palabras clave: marxismo, subsunción, historia, revolución, Kant.

Abstract: One of the fundamental tensions within Marx's writings arises from the complex relationship between the systematic and historical aspects of his description of capitalist society. This article argues that among all the concepts deployed by Marx 'subsumption' is key with respect to this issue. The different forms of capitalist subsumption analyzed by Marx designate the mechanisms by which capital shapes the developmental dynamics of modern societies. Yet the concept is undertheorized in Marx's writings and has been subject to divergent interpretations. Its implications remain contested. By returning to the philosophical origins of subsumption, in particular to Kant's 'critical' reconceptualization of it as a productive act of 'synthetic determination', this article seeks to establish its centrality for Marxist thought. Subsumption, it is argued, is the fundamental category of analysis linking capital as system to capital as history.

Keywords: Marxism, Subsumption, History, Revolution, Kant.

Recibido: I 8 de noviembre de 2020 Aceptado: I 5 de agosto de $202 \mathrm{I}$ https://dx.doi.org/IO.I 5 I 74/rv.vi 4i29.58 I 
Tna de las tensiones fundamentales en los escritos de Marx surge de la compleja relación entre los aspectos sistemáticos e históricos de su descripción de la sociedad capitalista. Un siglo y medio después de la publicación de El Capital -y a la luz de las aventuras históricas del comunismo que, en su mayor parte, deben considerarse como una acumulación de fracasos catastróficos- esta tensión sigue tanto dinamizando como atenuando la recepción del pensamiento de Marx, expresando sintomáticamente los fundamentos práctico-teóricos radicalmente distintivos y aun elusivos de su proyecto. Por una parte, el capital es representado por Marx como un conjunto de relaciones sociales que forman una totalidad aparentemente cerrada capaz de reproducirse puramente a través de su propio dinamismo interno. Por otra parte, Marx nos recuerda que el modo de producción capitalista no cae del cielo, sino que crece o se libera violentamente de las estructuras económicas del feudalismo, desarrollándose dentro y en antítesis con las relaciones y tecnologías del pasado. Para Marx, el sistema capitalista es un todo, una totalidad de relaciones entrelazadas que se presuponen y sostienen mutuamente. Pero al mismo tiempo, no es un todo con una existencia atemporal, independiente y que se mueva de manera autónoma, una esencia suspendida en el vacío. El capital no se desarrolla a partir de la nada, sino que es un fenómeno histórico sujeto a la emergencia y decadencia temporal en medio de toda una serie de "influjos perturbadores" (Marx, 2008: 6).

El "devenir" del capital como sistema depende, por lo tanto, de un modo de desarrollo que es simultáneamente una negación, absorción o negociación de las relaciones y formas sociales heredadas (de la riqueza, la tecnología, el conocimiento, las instituciones, las identidades, las prácticas, etc.) y su subordinación a la lógica del propio "proceso vital" del capital. Como relación social de produc- 
ción, ante todo, Marx describe, en unos pocos fragmentos dispersos (Marx, 1997: 54-77; Marx/Engels, 1988: 54-348; 1991: 372-387; 1994: 93-121) cómo el capital subordina -o "subsume"- formas de producción existentes para configurarlas como procesos de valorización capitalista, motores del beneficio para sus propietarios. Como señala Marx, esto puede ocurrir "formalmente", a través de una transformación de las relaciones económicas que intervienen en la producción (sustentada en la introducción de relaciones de intercambio entre compradores y vendedores de fuerza de trabajo). Pero la subsunción bajo el capital, señala Marx, también puede ocurrir y de hecho ocurre en una forma más profunda, "real", que transforma la composición material de la producción (las técnicas y la tecnología de la producción, así como los propios productos). Tanto en el plano económico como en el material, Marx identifica así los mecanismos por los que nacen las formas de dominación social específicamente capitalistas, que transforman los aparatos de producción y las relaciones de propiedad existentes para asegurar la extracción del excedente de mano de obra de los trabajadores en forma de plusvalía. Estos modos de subsunción "formales" y "reales" (junto con otras formas "híbridas" identificadas por Marx) constituyen los mecanismos de dominación a través de los cuales se logra el devenir del capital y el crecimiento de su poder para explotar y transformar la vida humana (Marx, 2009: 617-8).

Una vez que se ha producido un grado suficiente de tal subsunción, una vez que se ha incorporado y formado una masa suficiente de sustancia social de acuerdo con el proceso de vida del capital, entonces podría decirse que el sistema ya no es simplemente un devenir, sino que ha alcanzado el ser y, de forma infame, parece pararse sobre sus propias patas traseras independientemente de las manos humanas que lo animan. Marx describe el "ser" del capital como un sistema orgánico, es decir, un sistema capaz de reproducir sus propias condiciones de existencia. Sin embargo, a diferencia de 
otros sistemas orgánicos, la peculiaridad del capital es su necesidad de expandirse, de acumularse. Por definición, el capital no puede sobrevivir "simplemente" reproduciéndose a sí mismo, regenerándose exactamente como estaba cuando comenzó su ciclo de vida. Debe, más bien, reproducirse a sí mismo de forma expandida, es impulsado hacia adelante y hacia afuera para absorber una riqueza cada vez mayor de material que puede reclamar como propio a través de la mercantilización, la explotación y la acumulación. El ser del capital no implica, pues, ni descanso ni estancamiento, sino más bien un constante devenir, un crecimiento constante, una espiral hacia fuera de su energía centrípeta que choca con múltiples barreras: la resistencia de los trabajadores, la finitud de la naturale$\mathrm{za}$, incluso contra su propio impulso destructivo de acumulación insaciable.

Si el devenir del valor hacia más valor, su expansión axiomática, es sistemáticamente presupuesta y requerida por el capital, ¿cómo se correlaciona esto con el otro devenir del capital, su devenir histórico (y su eventual muerte anticipada) como una forma finita de producción social? ¿Cuándo, cómo y como efecto de qué fuerzas sociales terminará el reinado del capital sobre la vida humana?

\section{2. (Im)posibilidades revolucionarias}

Como es bien sabido, para Marx estas eran ante todo cuestiones prácticas, que sin embargo generaron una prolífica reflexión teórica. En la tensión que surge entre el ser y el devenir del capital, su "coherencia orgánica” y su transitoriedad histórica, la problemática marxista de la revolución es central. ¿Sigue la revolución un arco progresivo de la necesidad, que surge en la actualidad cuando para el capital "su tiempo ha llegado"? o jla revolución comunista subsiste más bien dentro y contra el capital desde su comienzo, como la posibilidad siempre presente de superación que alberga inma- 
nentemente en su interior? La postura objetivista de la primera, para la cual la revolución sigue una teleología cuasi naturalista o divina, independiente de cualquier deseo e intención individual, se invierte en el subjetivismo de la segunda, para la cual la revolución emerge como la interrupción voluntaria de la normalidad capitalista, el "freno de emergencia" de Walter Benjamin en el tren del progreso histórico (Benjamin, 2008: 70). A la luz de las múltiples derrotas del comunismo y de la instalación monopolística del capitalismo como único paradigma económico del sistema mundial moderno, ninguno de los dos puntos de vista parece ofrecer un horizonte particularmente creíble de anticipación revolucionaria. Para el objetivista histórico, podemos preguntarnos ¿cuándo? Para el subjetivista, podemos preguntar ¿por quién? Además, en ausencia de un desafío revolucionario al reino del capital, ¿como debemos comprender su desarrollo incontrolado? ¿Podría el ser-devenir del capital acercarse a un punto de total absorción y saturación del mundo de la vida humana, no solo "formalmente", sino también "realmente”? ¿Podría ser que este punto ya ha sido cruzado, dejándonos en un abismo "post-histórico" sin salida?

Debido a sus consecuencias implícitas para las características y la organización de la producción, y por lo tanto también para las luchas que surgen de la producción, la conceptualización provisional y fragmentaria de Marx sobre la subsunción capitalista ha proporcionado un punto focal evocador para los debates en torno a las transformaciones (o la muerte) de la política revolucionaria orientada al trabajo. Si el comunismo es ante todo un movimiento obrero, y la experiencia del trabajo está moldeada por las formas particulares de dominación que operan en la producción, entonces un análisis de estas formas y su evolución ofrecería como mínimo un punto de partida, si no un modelo comprensivo, para comprometerse críticamente con las trayectorias de lucha que tienen 
como horizonte último la superación de las relaciones sociales capitalistas.

Para los pensadores marxistas, preocupados por el destino histórico de la revolución, la subsunción ha proporcionado un vocabulario técnico con el que se puede designar la relación evolutiva entre los mecanismos específicos de poder y la dinámica general del sistema capitalista, entre la experiencia de sujeción al mando del capital y las tendencias directrices de la acumulación. Se ha considerado que una teoría de la subsunción ofrecía la clave para comprender no solo el camino "objetivo" del desarrollo capitalista, sino también los programas "subjetivos" de resistencia al mismo, uniendo así la configuración de las condiciones desde las que debe surgir la revolución.

Esta recepción de la subsunción dentro de la teoría marxista ha sido a su vez creativa y conservadora, desplegada para diagnosticar los cambios epocales del poder capitalista sobre la sociedad en su conjunto (como un movimiento lineal a través de fases de subsunción "formal", "real" y eventualmente "total") o para reafirmar la consistencia de una lógica básica que gobierna cada instancia existente y posible de socialización capitalista. Es decir, las interpretaciones de la teoría han caído en gran medida en un lado de la tensión entre la historia y el sistema con el que comenzó nuestra discusión. No es necesario ensayar estos debates aquí, salvo para señalar que si bien la última tendencia puede reclamar una mayor coherencia conceptual y una mayor fidelidad a los textos de Marx, es la primera la que ha sido más enérgica para los debates críticos, captando el sentimiento generalizado -aunque borroso- de que el poder capitalista ha evolucionado y se ha intensificado hasta tal punto que ahora invade e interfiere en todos los aspectos de nuestras vidas, sin ofrecer ninguna salida aparente. La subsunción real, por consiguiente, ha llegado a ser para muchos un tópico para el imperioso encierro de la vida por el capital, como el mapa descrito 
en el fragmento de Borges que cubre completamente el territorio que representa, coincidiendo con él punto por punto (1960: 119). Ya no restringida en sus efectos a la "racionalización" de los procesos de trabajo discretos, la lógica de coacción y eficiencia técnica del capital penetraría y transformaría, en esta lectura, la totalidad de la existencia humana de tal manera que, en la formulación de Negri, "la sociedad misma se ha convertido en una fábrica" (2003: 105) o en el pronóstico de Adorno, "la 'alteración de la composición técnica del capital' se prolonga dentro de las que engloban, e incluso constituyen, las exigencias tecnológicas del proceso de producción" (2005: 229). No es solo el trabajo del trabajador un quantum específico de su tiempo- el que se convierte aquí en "uno de los modos de existencia del capital", sino toda la vida del trabajador (y, de hecho, del no-trabajador), lo humano como tal, individual y colectivamente, en su ser interior y exterior. Esta concepción de la subsunción real (o en algunas variantes "total") abarcaría así todo lo que el capital ha hecho y sigue haciendo a nuestro mundo y a nosotros mismos, circunscribiendo al mismo tiempo el terreno evanescente de las posibilidades revolucionarias -sus imposibilidades tendenciales o incluso consumadas-.

Como han señalado varios críticos, tales interpretaciones de la subsunción implican un cortocircuito teórico, por el que la lógica del poder propia de la producción capitalista se traslada a la totalidad social de manera no mediata y absolutizada, sacrificando un funcionamiento matizado del aparato crítico de Marx en favor de un diagnóstico retórico sensacionalista sobre el presente. Quienes han tratado de demostrar la mala interpretación de Marx que está en juego en estos intentos de cartografiar la subsunción formal y real en las fases históricas de la sociedad capitalista, por el contrario, se han esforzado por reinsertar la teoría de la subsunción en un relato sistemático del capital. Sin embargo, la dificultad estriba en que, si bien las diferentes formas de subsunción en la produc- 
ción no corresponden directamente a distintas fases del desarrollo capitalista mundial, esas formas -en particular la subsunción real- tienen profundos efectos transformadores que se extienden a la esfera más amplia de la vida y remodelan el contexto general de la acción y la lucha sociales. La base teórica segura que ofrece un relato sistemático del ser del capital permanece esencialmente en silencio sobre la cuestión del devenir histórico del capital (y su superación), salvo por la afirmación de las leyes y tendencias de acumulación invariables que supuestamente rigen la trayectoria de su desarrollo. El resultado es un desacoplamiento del sistema de su historia que lo "congela" en el tiempo. Queda así claro que, a pesar de su aparente oposición, ambas interpretaciones de la subsunción -la sistemática y la historicista- refuerzan la idea de que, a nivel ideológico y práctico, el capital ha logrado efectivamente la supresión de su propia sujeción a la finitud histórica.

Sin embargo, la subsunción tiene un estatus privilegiado dentro del aparato conceptual marxista precisamente porque marca la interfaz entre el capital como sistema y el capital como historia. Mientras que categorías como 'valor', 'mercancía' y 'capital' son internas a la totalidad de las determinaciones de la forma capitalista, la subsunción designa el punto de articulación entre este "sistema en proceso" orgánico y la sustancia histórica a través de la cual vive, que debe absorber y reformar para poder existir. Como hemos visto, solo a través de la subsunción de las formas de producción social existentes el capital puede surgir y establecerse. Y aun cuando esto haya ocurrido en su forma "real", insiste Marx, continúa remodelando radicalmente "todas sus condiciones sociales y tecnológicas" (Marx/Engels, 1994: 30) a través de "una revolución continua en la producción” (Marx/Engels, 1997: 15). La subsunción es, pues, la categoría de mediación que relaciona el sistema capitalista con sus fundamentos externos e internos, que por necesidad están sujetos al flujo del tiempo histórico. Lo que 
indica la subsunción es, por lo tanto, lo que une al capital como sistema con la historia en la que reside y sobre la que actúa.

¿Qué es, entonces, lo que indica la subsunción? Aquí es donde reside el problema. Dado el esquema rudimentario de Marx de la subsunción, su aparición provisional en borradores y notas y el hecho de que no se haya integrado en la versión final de El Capital, el peso que parece tener como categoría principal de mediación entre los aspectos sistemáticos e históricos de El Capital no se apoya en un marco conceptual desarrollado. Al carecer de un aparato robusto propio, la teoría de la subsunción se ha subordinado, como resultado, a dos esquemas de totalidad que compiten entre sí y que han dominado el pensamiento marxista: una dialéctica sistemática que totaliza sincrónicamente y una filosofía de la historia que totaliza diacrónicamente. Cada una de ellas funciona a su manera para desarmar la tensión revolucionaria entre la forma y el contenido del capital, entre el sistema y su historia, entre el ideal perfecto y la materialidad imperfecta de la explotación. Para reactivar esta tensión en el plano de la teoría, de manera que el marxismo pueda seguir siendo operable como un discurso que sigue el movimiento de un sistema dinámico e inestable, de condiciones concretas que deforman continuamente su propio espacio de posibilidades (Longo/Longo, 2020) es necesario explorar qué es exactamente lo que está en juego en la categoría de subsunción, tanto en su prehistoria filosófica como en el paso que la lleva a convertirse en una categoría materialista adecuada a la crítica de la dominación capitalista.

\section{Un concepto "crítico" de subsunción}

La subsunción se entiende ampliamente como un concepto de clasificación o categorización. En su forma filosófica más abstracta y general, designa una relación de pertenencia a una clase de cosas, de incorporación a una categoría más general o a una unidad formal, ya 
que los particulares se relacionan con un universal, o las especies con un género. Tradicionalmente, pues, la subsunción se ha referido al problema de la ordenación u organización, de establecer una jerarquía entre los términos, que van de lo más particular a lo más general. Platón está subsumido en el género "hombre", que a su vez está subsumido en el género "animal”, y así sucesivamente. Las raíces de tal jerarquía se encuentran en el esquema taxonómico del ser de Aristóteles, formalizado gráficamente en el pensamiento medieval como "árbol de Porfirio".

A primera vista, el uso de la subsunción por parte de Kant parece conservar su forma directa y tradicionalmente lógica. De hecho, la "lógica trascendental" que Kant desarrolló y dentro de la cual figura su recuento de la subsunción, se modeló sobre la "lógica general" esbozada anteriormente. Pero Kant añade una nueva y muy significativa dimensión al problema de cómo se puede emitir un juicio de subsunción: la de la heterogeneidad entre los elementos que deben relacionarse en el juicio. No se preguntó por la subsunción en su sentido lógico formal, como conexión ordenada de las determinaciones del pensamiento. Más bien, al analizar las condiciones de posibilidad de cualquier experiencia de un objeto, se preguntó cómo la sensibilidad y el entendimiento -facultades cognitivas que son "totalmente no homogéneas" entre sí, y que, por lo tanto, generan representaciones que son diferentes en su tipo- pueden subsumir al conectarse. Esto es un problema porque, "en todas las subsunciones de un objeto bajo un concepto las representaciones del primero deben ser homogéneas con el segundo" (Kant, 1990: A137/B176). La homogeneidad es necesaria porque la subsunción siempre implica identidad: se dice que lo que se subsume bajo una categoría es una instancia particular de esa categoría, mientras que la categoría subsumida "inhiere" en lo particular, es decir, se encarna en ella. Lo que se subsume bajo alguna categoría o forma es esa categoría o forma, en algún sentido básico especifi- 
cado por la naturaleza del sistema ("Sócrates" es un hombre y "el hombre” está encarnado en Sócrates). Pero mientras que la subsunción lógica se ocupa de elementos universales y particulares del mismo tipo (representaciones conceptuales) que solo tienen que ubicarse adecuadamente dentro del sistema según su generalidad y especificidad ("animal" es superior a "hombre" pero distinto de "mineral", etc.) la subsunción trascendental se ocupa de elementos no conceptuales (representaciones sensibles) que, sin embargo, deben subsumirse en conceptos. ¿Cómo es posible esta identidad entre elementos no conceptuales? ¿Cómo se pueden adaptar las sensaciones a los conceptos, de manera que se puedan presentar como "pertenecientes" a ellos? Este es el problema básico de la subsunción en su forma "crítica".

La solución de Kant a este problema se basa en la identificación de un acto productivo de "determinación de la forma" por el cual las representaciones sensibles se constituyen como particularidades de los conceptos, y, por lo tanto, pueden presentarse como subsumidas a ellos. Más allá de una distribución relacional de elementos homogéneos, situados en el nivel apropiado según su rango en la jerarquía sistémica, Kant expone una mecánica de producción cognitiva por la que cualquier particular subsumido bajo un concepto debe haber sido producido primero como un particular a través de un acto de determinación de la forma (un “juicio”). El elemento particular debe haber sido reelaborado y dotado de forma conceptual para poder participar en la economía interna del sistema.

Para Kant, esta determinación de la forma se produce mediante la disolución de la forma espontánea y singular de la unidad que el objeto tiene inicialmente al ser recibido por los sentidos, y su posterior rearticulación según un esquema genérico de relaciones conceptuales. A través de este proceso productivo, todo objeto de experiencia llega a compartir el mismo conjunto básico de deter- 
minaciones organizadoras, una forma universal de objetividad común a toda experiencia subjetiva. Las representaciones sensibles quedan subsumidas bajo los "conceptos puros del entendimiento", de modo que algo "impensable" se convierte en "pensable", algo privado se convierte en comunicable. La configuración de una primera serie "dada" (datos de los sentidos) se disecciona y se vuelven a sintetizar sus elementos según la lógica de una segunda serie dominante (conceptos puros) que determina su unidad de una nueva manera. Esos elementos, en su nueva forma interconectada, instancian ahora la "forma" universal y abstracta de la objetividad en un objeto concreto y particular (para Kant, los conceptos abstractos y "vacíos" se llenan de un "contenido" sensible). De esta manera, los elementos de la primera serie se subsumen en la segunda serie a través de un proceso de determinación sintética. Este proceso forma el objeto de manera genérica, de modo que puede relacionarse y compararse con otros objetos y así integrarse en el sistema (de la experiencia autoconsciente) según su lugar apropiado.

Así pues, Kant muestra que solo mediante la determinación unificadora de la "síntesis trascendental" puede producirse la identidad (de lo particular y lo universal) implícita en la subsunción. En lugar de explorar únicamente la forma en que los particulares se relacionan con los universales, también se plantea la cuestión de cómo las entidades individuales o singulares se forman primero como instantes particulares de una categoría general. El problema de la subsunción no consiste en encajar elementos aislados en una estructura predeterminada de manera naturalista o teísta (es decir, asumiendo su conmensurabilidad preordenada y su pertenencia a un orden armonioso), sino en la reconfiguración apropiativa de una serie o en la distribución topológica según una segunda; un forzamiento logrado por división y recomposición. El modelo de Kant es un modelo de producción, una fusión de elementos que en sí mismos no se "pertenecen” uno al otro. Más importante aún, 
no se trata simplemente de que los dos tipos de representación (conceptos e intuiciones sensibles) en la relación subsuntiva sean heterogéneos per se, sino que poseen tipos de unidad que obedecen a lógicas de composición heterogéneas (la estética y la discursiva). El relato de Kant sobre la síntesis trascendental se centra en la negación de un tipo de unidad u organización ajena a la lógica dominante y su reconfiguración según otra, permitiendo así que la entidad subsumida sea absorbida en el marco de un sistema.

\section{2. Subsunción y sistema}

Este es el problema más profundo y "crítico" de la subsunción que Kant establece y dentro del cual se inscribe el uso de la subsunción por parte de Marx; un problema que llega a los fundamentos de la sistematicidad, preguntando qué procesos fundamentan el surgimiento de un conjunto básico y objetivo de relaciones y formas, en lugar de tomar esas relaciones y formas como dadas por la naturaleza. Este marca el umbral en el que el discurso de la subsunción pasa de la estructura a la génesis, de la ordenación taxonómica a un análisis genético de la homogeneidad formal que presupone toda taxonomía, de un problema de reconocimiento a uno de constitución.

Sin embargo, el reconocimiento de la transición teórica de determinados elementos a los procesos de su formación no agota el alcance de la transformación que sufre la subsunción en esta fase crítica del pensamiento, cuyos interrogantes van desde la pura razón a la economía política. La cuestión central que abre la intervención de Kant es la siguiente: si la subsunción no es simplemente el reconocimiento y la distribución de elementos dentro de un sistema, sino que depende del proceso productivo de síntesis por el que cada entidad subsumida se forma como una instancia particular de lo universal que la subsume, ¿cuál es la naturaleza de 
este proceso formativo? ¿De qué hablamos cuando hablamos de la determinación de lo que se subsume? ¿Cómo "funciona" la división y la recomposición sintética?

Kant ofrece respuestas notoriamente técnicas e intrincadas a estas preguntas, que se basan en última instancia en una reelaboración innovadora de las concepciones clásicas y modernas tempranas sobre el funcionamiento del intelecto. En este sentido, su relato sobre la determinación de la forma de los objetos de la experiencia tiene un carácter eminentemente idealista: se produce como un "juicio", implica múltiples procedimientos de cognición y genera efectos puramente subjetivos que no reclaman las cosas tal como son en sí mismas. Sin embargo, por muy inconscientemente que se presente, hay indudablemente un impulso proto-materialista en el relato de Kant sobre la subsunción en la medida en que reconoce la heterogeneidad y resistencia de la materialidad del "contenido" sensible que debe formarse conceptualmente para que se genere esa objetividad. A diferencia de Hegel, para quien el contenido y la forma parecen simplemente exteriores entre sí, pero en realidad están vinculados orgánicamente como momentos necesarios de una única "idea” abarcadora, Kant reconoce que la subsunción implica una especie de transición arbitraria o contingente entre diversas lógicas de composición. No hay nada en las representaciones sensatas como tales que requiera su reconfiguración discursiva (existen seres que sienten, pero no piensan). Pero como el sistema en el que se van a internalizar estas representaciones es de carácter discursivo, exige esta reconfiguración para poder incorporarlas. El sistema debe formar la materia que necesita para funcionar, y vive más cuanto más forma (de lo contrario, dice Kant, la forma conceptual sin contenido sensible permanece "vacía", sin vida). Esta opinión fue el resultado de la aceptación de Kant de que no había ninguna garantía metafísica o lógica que sustentara una correspondencia entre el orden de nuestra experiencia y un orden "real” de cosas 
fuera de la mente. Esta proposición significaba que el sujeto no podía simplemente "intuir" el orden del universo, sino que tenía que generarlo en primer lugar. A menos que uno se adhiera a la noción de un orden "puro" o absoluto de formas establecido por un dios creador, uno se ve obligado a reconocer que todo sistema distinto depende de la formación de un contenido o sustancia que obedece a lógicas de composición diversas y heterogéneas, es decir, depende del acto de producción. Así pues, un sistema vive en la medida en que puede determinar con éxito la forma de esta sustancia de acuerdo con su propia lógica, es decir, producirla como un momento de su propia existencia y así subsumirla.

\section{El materialismo metabólico}

El gran invento de Marx, que establecería las bases de su relato de la subsunción capitalista, fue retomar esta visión y reposarla en términos materialistas. Para Marx, el inmenso poder de determinación de la forma que era central en el idealismo alemán fue socavado por su limitación a procesos de carácter subjetivo e ideal, a la teoría más que a la práctica. Marx trató de liberar la fuerza de esta síntesis fundando la determinación de la forma no en la dinámica de la cognición - procesos de análisis y síntesis conceptual, juicio y silogismo- sino más bien en lo que, siguiendo a Feuerbach, denominó enfáticamente la "vida real" de los "individuos reales"; una noción de la vida fundada en carne y hueso humano en lugar de ideas enrarecidas. De esta manera, el primer "humanismo" de Marx recodificó la concepción del idealismo alemán de una actividad subjetiva que se desarrolla en un dominio ideal abstracto, transformándola en una concepción de actividad objetiva (gegenständliche Tätigkeit) que se desarrolla en el dominio material de las interacciones hombre-naturaleza. Marx teorizó la estructura esencial de estas interacciones prácticas con creciente precisión a lo 
largo de sus escritos, conceptualizándolas como trabajo y, más ampliamente, como producción. La síntesis que sustenta la subsunción capitalista deriva su contenido de esta concepción materialista de la actividad humana "real" como producción: un proceso de determinación de la forma basado en la relación transformadora y de apropiación entre los individuos sociales y su entorno material.

El desarrollo de un relato materialista de la subsunción implicaba, pues, reconstruir (en lugar de rechazar) el relato idealista de la determinación de la forma, según el carácter y las limitaciones de la relación hombre-naturaleza tal como se desarrolla en el escenario de la historia, más que según el carácter y las limitaciones de la cognición discursiva tal como se desarrollan en un sujeto racional "puro". De manera crucial, a partir de los años 1850, Marx comenzó a conceptualizar la actividad productiva como vinculada a las leyes conservacionistas de intercambio metabólico (el intercambio de materia y energía entre un sistema orgánico y su entorno), estipulando que el trabajo humano "solo puede proceder como la naturaleza misma, vale decir, cambiando, simplemente, la forma de los materiales" sobre los que trabaja, a través de "juntar y separar" en lugar de los puros actos de "creación real" (Marx, 2008: 53). Al igual que en Kant, la determinación de la forma se produce aquí mediante la disolución de alguna organización anterior del "contenido" y su posterior sintetización según un nuevo esquema de objetividad (Cfr. Echeverría, 1998: 3). Sin embargo, la reconceptualización metabólica de Marx de este proceso no solo establece limitaciones materiales (más que cognitivas) sobre cómo puede ocurrir, sino que funda la objetividad del producto resultante en una lógica de la forma totalmente diferente, en la que la instrumentalidad práctica, más que la pura racionalidad, es el principio rector. Por consiguiente, mediante el trabajo, a medida que se desarrolla en un proceso de producción técnicamente estructurado, los agentes humanos son capaces de apropiarse de 
la materia y la energía en sus formas naturales que se producen "espontáneamente" y reconfigurarla para producir nuevas formas "sintéticas" de objetividad que satisfagan más eficazmente sus necesidades y deseos. La noción de "forma" que está en juego aquí, no denota simplemente alguna nueva organización física del material (aunque esta es una condición necesaria), sino el fin instrumental al que el material está destinado a servir (por ejemplo, la satisfacción del hambre, o la tala de árboles). El trabajo promulga así la subsunción de material físico bajo un fin práctico, una forma-determinación del material que lo dota de una novedosa o mayor utilidad.

Las formas objetivas que se producen de este modo -lo que en el contexto del análisis de Marx de la mercancía se denominan "valores de uso" - son formas cuya posibilidad está condicionada por las propiedades y limitaciones inherentes de los materiales naturales de los que están compuestos. Sin embargo, este condicionamiento solo impone una limitación a lo que los humanos pueden producir y a cómo lo producen. Dentro del marco materialista de Marx no hay una conexión necesaria que lleve del contenido (material natural) a la forma (cosa útil en la práctica). En cambio, como Marx afirma repetidamente, esta conexión varía de manera contingente a través del tiempo y el lugar, siendo siempre determinada por una sociedad particular y su "modo de producción" (Marx, 1976: 145). Además, como insiste Marx, las necesidades que deben satisfacerse mediante la producción de valores de uso son en sí mismas variables y evolucionan en relación con el desarrollo de la producción: las nuevas formas de producción generan nuevas necesidades en una incesante espiral creativa que describe el devenir de la historia.

Hay dos sentidos básicos de subsunción operativos en este esquema general de la reproducción social, antes de su especificación como reproducción social capitalista. En primer lugar, la subsun- 
ción de alguna masa de material (que se encuentra en una configuración natural o histórica) bajo formas prácticas de objetividad, que está implícita en todo acto de trabajo. En segundo lugar, la subsunción de los individuos sociales (los que producen) bajo un "modo de producción" que regula su actividad laboral a través de una conjunción particular de relaciones sociales y fuerzas técnicas (Marx, 2007a: 17). Ambos son procesos que determinan una forma de unidad histórica y socialmente específica entre elementos cuya unidad previa debe disolverse primero (una unidad "objetiva" previa: el árbol; un modo de producción previo: el feudalismo).

\section{La subsunción capitalista}

Cuando Marx habla de la subsunción capitalista -más precisamente, de la subsunción "formal" y "real" del trabajo bajo el capital- se presupone todo este modelo de determinación de la forma metabólica y de reproducción social. Para Marx, la subsunción del trabajo bajo el capital es una abreviatura que expresa abstractamente, como una relación entre dos elementos, lo que de hecho es una relación entre dos procesos: el proceso de trabajo y el proceso de valorización. En esta relación, el proceso de trabajo (la actividad metabólica de determinación práctica de la forma que se ha esbozado anteriormente) se subsume en el proceso de valorización (el aumento "milagroso" del capital logrado simplemente a través de las metamorfosis cíclicas de sus formas). A través de su subsunción bajo el proceso de valorización el proceso de trabajo adquiere una nueva "forma" o lógica de organización, convirtiéndose repentinamente en algo completamente diferente a lo que históricamente ha sido su propósito principal. Ya no se orienta hacia la satisfacción de las necesidades (por muy desigual que haya sido la distribución de la satisfacción entre los individuos y las clases sociales) sino que ahora sirve al objetivo de aumentar la riqueza abstracta y ampliar la 
producción. En esta nueva forma, el proceso de trabajo se convierte en el motor material de la acumulación económica, un aspecto o momento subordinado de los procesos de vida del capital:

El proceso de trabajo -que, debido a su carácter abstracto, a su sustancialidad pura, es inherente a todas las formas de producción por igual-como punto de partida puesto antes del valor se presente nuevamente dentro del capital, como un proceso que ocurre dentro de su sustancia, que constituye su contenido (Marx, 2007a: 245).

La subsunción formal y real describe estrategias o mecanismos por los que el proceso de trabajo se adapta o se reconfigura de tal manera que se convierte en un proceso de valorización y, por lo tanto, puede integrarse efectivamente en el sistema de acumulación capitalista. Se trata principalmente de subordinar el objetivo intrínseco del trabajo (la producción de valores de uso) al objetivo de la valorización (la producción de plusvalor), de modo que la acumulación de capital, más que la satisfacción de las necesidades sociales, pasa a ser la lógica principal de organización (la "forma”) que rige la producción. Dado que la producción de plusvalor solo se logra mediante la explotación de la mano de obra excedente, se trata de mecanismos para asegurar y perfeccionar la explotación del trabajo.

Como ha señalado Patrick Murray (2004) el contraste entre la subsunción formal y la real establece una distinción entre los mecanismos "sociales" y "materiales" de determinación de la forma del proceso de trabajo (aunque, por supuesto, en un sentido menos directo lo social es siempre material y viceversa). Centrándose en el funcionamiento de esos mecanismos, es fundamental subrayar que esa determinación de la forma ocurre como un proceso de dominación y explotación, que la subsunción capitalista no es un proceso "automático" impulsado por una lógica de necesidad 
natural, sino un proceso social inherentemente antagónico y controvertido. Al esforzarse por determinar el proceso de trabajo en una nueva forma que corresponde al fin de la valorización (fin intrínsecamente contradictorio con los intereses y el bienestar de los trabajadores), el capital se encuentra con una materialidad resistente, barreras "renuentes pero elásticas" (Marx, 2009: 491). No se trata simplemente de la resistencia de una materialidad "pasiva", como ocurre en todo acto de trabajo, la inercia de toda forma natural que pretende permanecer tal cual contra la fuerza de la entropía (si se puede decir que la naturaleza es "pasiva” de esta manera); sino de la materialidad "activa" de la subjetividad de los trabajadores, una subjetividad capaz de plantear sus propios fines conflictivos. Por un lado, podemos hablar de la resistencia "activa" del trabajo a su explotación por el capitalista, de la ruptura entre las dos reivindicaciones laborales que Marx dramatizó en su capítulo sobre la jornada laboral: la reivindicación del trabajador sobre su propio cuerpo (que lleva la capacidad de trabajo) y la reivindicación del capitalista sobre la mercancía que ha comprado (el uso de esa capacidad) (Marx, 2008: 280-1). Por otra parte, la subsunción real expresa claramente una estrategia de maximización de esta explotación por otros medios que el mando interpersonal directo. Es decir, en lugar de confiar en la disciplina de gestión y en la amenaza del desempleo para motivar la productividad del trabajador, los propietarios del proceso de producción pueden reconfigurar su estructura técnica para hacer de la explotación de los trabajadores una característica objetiva de ese proceso. Aquí, el trabajador debe trabajar no porque un capitalista lo ordene, sino porque los medios de producción lo hacen. El proceso de trabajo en sí mismo está diseñado para explotar al trabajador y, por lo tanto, para poder trabajar en absoluto, el trabajador debe someterse a este aparato objetivo de dominación, convirtiéndose en un medio para su fin y no viceversa. 
Esta inversión de los medios y fines de la producción está en el centro del problema de la subsunción real, que Marx describe como la transformación del poder, la explotación y la alienación capitalistas en un "hecho tecnológico" (Marx/Engels, 1994: 30). Sin embargo, el significado de la subsunción real no se limita al contexto inmediato de la explotación y la sujeción del trabajador en la producción, sino que también tiene que ver con el problema más amplio del ser y el devenir histórico del capital. Con la creciente complejidad y el carácter integrado de las formas instrumentales que han surgido en la modernidad, y cuya constante revolución se presupone en la acumulación capitalista, los medios de producción social, tomados en su conjunto, plantean la amenaza de encerrar a la humanidad en las lógicas sociales del presente -es decir, las lógicas destructivas de la dominación de clase y la acumulación de capital sin límites- a medida que se van "incorporando" cada vez más a los aparatos técnicos de los que depende la humanidad para vivir. Impulsados por la competencia, los capitalistas se esfuerzan incesantemente por aplicar formas cada vez más eficaces para aumentar la productividad y la explotabilidad del trabajo, pero al transformar el proceso de trabajo estos efectos se desangran en el resto de la sociedad, que después de todo está compuesta materialmente por todos los productos que resultan de estos distintos procesos de trabajo. Gradualmente, los patrones de consumo, la formación de identidades, las instituciones sociales, la infraestructura y la comunicación, las relaciones internacionales -en resumen, todo el mundo de la vida humana- llega a ser remodelado por los efectos de un proceso cuya lógica motriz es la acumulación de capital.

Sin embargo, en cualquier grado que esta vasta maquinaria de dominación se expanda y envuelva la totalidad de lo que podríamos llamar la vida humana hemos visto que el poder del capital está arraigado en su esfuerzo por controlar la producción, en su 
subsunción del proceso de trabajo en el que se decide la forma práctica y el propósito instrumental de los medios de existencia social. Esta subsunción, sin embargo, está dividida por la tensión y el conflicto, lo que revela la lucha en el centro del intento de integrar la materialidad resistente del trabajo al sistema de formas sociales capitalistas. En su resistencia, el trabajo expresa su ser como algo más que meramente idéntico a la forma y el objetivo bajo el que se subsume en este sistema (un sistema en el que aparece como "capital variable"). Es un elemento que se niega a someterse a la nueva síntesis que se le impone, ya sea de manera recalcitrante o proponiendo otra síntesis en conjunto. Lo que está en juego aquí no es simplemente el control y la autonomía de los trabajadores, sino que el metabolismo humano termine al servicio de la naturaleza. La subsunción capitalista implica una lucha sobre la determinación de la forma de este metabolismo (como un "proceso de trabajo") y su producto, que por implicación es también una lucha indirecta sobre la determinación de la forma de la sociedad en su conjunto. Es en este sentido que podemos entender la subsunción real como el punto crucial de mediación entre el ser abstracto del capital como sistema y su devenir histórico concreto. Al apropiarse del metabolismo humano con la naturaleza, el capital ha secuestrado el mecanismo práctico mediante el cual las sociedades humanas reproducen su vida y su mundo, subvirtiendo la interacción cualitativamente evolutiva entre las capacidades productivas y las necesidades de consumo (la base de todo devenir histórico). Si bien este metabolismo ha servido durante gran parte de la historia para sostener contextos de explotación y dominación de clase, la especificidad de su subsunción por el capital es su reorientación hacia un fin abstracto, puramente cuantitativo. Por eso Marx afirma que, a través de la subsunción real, "es el capital el que primero ha capturado el progreso histórico poniéndolo al servicio de la riqueza" (Marx, 2007b: 92). 


\section{Conclusión}

¿Era necesario tomar este desvío kantiano, a través de los conceptos, la cognición, la síntesis y la determinación de la forma, para abordar adecuadamente la relación entre el capital como sistema y el capital como historia? ¿O para circunscribir el problema de la subsunción real y sus implicaciones en las luchas revolucionarias? No es difícil anticipar las críticas que podría suscitar un encuadre "filosófico" de estos problemas, un encuadre que a primera vista puede parecer que hace retroceder a Marx al campo teórico del que trató tan intensamente de escapar en los primeros años de su formación intelectual. Sin embargo, paradójicamente, solo abordando la refundación crítica de la subsunción que se produce dentro de la filosofía kantiana podemos apreciar el pleno significado de esta categoría para el materialismo desarrollado por Marx y la crítica de la economía política. No se trata de una negación abstracta del punto de vista filosófico, sino de un caso que se apropia de sus elementos mientras trasciende sus límites.

Hemos visto cómo dos aspectos proto-materialistas de la subsunción en el pensamiento de Kant abren la posibilidad de que Marx reelabore y despliegue la subsunción. En primer lugar, el reconocimiento de que la "materia" está diferenciada internamente, u organizada según lógicas heterogéneas de la forma (discursiva, estética, etc.). En segundo lugar (y relacionado), el rechazo de una internalización "naturalista" de todas las formas dentro de un sistema de ser único y cerrado, y de un espacio de posibilidades, un modelo creacionista de la causalidad de las cosas que garantizaría de antemano su unidad coperteneciente y armoniosa. Los compromisos precríticos que Kant y Marx rechazan conceptualizan la subsunción como poco más que la disposición jerárquica de entidades ya dadas, una ubicación de las cosas en su lugar apropiado 
dentro del orden de la creación. El modelo de Kant, por el contrario, es el de la producción: una fusión sintética de elementos que no pertenecen en sí mismos. Esto permite que el problema de la subsunción se plantee como doble. En primer lugar, ¿cómo (o por cual proceso) se determina la forma? En segundo lugar, ¿qué formas deben determinarse? Ambos aspectos de la subsunción se relativizan según la especificidad del contexto sistémico en el que se produce la subsunción.

Apropiándose e intensificando estas innovaciones kantianas, la elaboración crítica de la subsunción como determinación sintética de la forma es arrancada por Marx de su contexto idealista ("cognición”) y recodificada como descripción del proceso metabólico de la producción material ("práctica"). En la medida en que el capital se conceptualiza como un sistema de formas sociales a través del cual se organiza y dirige la producción material (un "modo de producción”), este sistema posee actualidad histórica en la medida en que subsume (y, por tanto, transforma) las formas de producción existentes de tal manera que se convierten en procesos de producción capitalista, con todas las repercusiones sociales y materiales que hemos visto que se derivan de ello. Diferentes formas de subsunción capitalista (formal, real, híbrida) designan las diferentes modalidades de este proceso de reconfiguración de la producción y dominación de los trabajadores y, por lo tanto, diferentes articulaciones de la lógica abstracta de la acumulación capitalista con formas históricas concretas de producción y reproducción social.

\section{Bibliografía}

Adorno, Theodor W., 2005, Minima Moralia: Reflections from Damaged Life, Verso, Londres / Nueva York.

Benjamin, Walter, 2008, Tesis Sobre la Historia y Otros Fragmentos, Itaca / UACM, México. 
Borges, Jorge Luis, 1960, El Hacedor, Alianza, Madrid.

Echeverría, Bolívar, 1998, La contradicción del valor y del valor de uso en El Capital de Karl Marx, Itaca, México.

Horkheimer, Max, 1972, "Traditional and Critical Theory", en Critical Theory: Selected Essays, Continuum, Nueva York, pp. 188-243.

Kant, Immanuel, 1990, Kritik der reinen Vernuft I, Suhrkamp, Frankfurt.

Longo, Giuseppe y Sara Longo, 2020, "Infinity of God and Space of Men in Painting, Conditions of Possibility for the Scientific Revolution", en Mathematics in the Visual Arts, ISTE-Wiley, Nueva York.

Marx, Karl, 1997, El Capital Libro I Capitulo VI (inédito), Siglo xxI, México.

, 2007a, Elementos Fundamentales para la Critica de la Economía Política 1857-1858, vol. 1, Siglo XXI, México.

, 2007b, Elementos Fundamentales para la Critica de la Economía Política 1857-1858, vol. 2, Siglo xxI, México.

, 2008, El capital, t. I, vol. 1, Siglo xxI, México.

, 2009, El capital, t. I, vol. 2, Siglo xxI, México

Marx, Karl y Friedrich Engels, 1988, Collected Works, vol. 30, Lawrence \& Wishart, Londres.

, 1991, Collected Works, vol. 33, Lawrence \& Wishart, Londres.

1994, Collected Works, vol. 34, Lawrence \& Wishart, Londres.

, 1997, Manifiesto del Partido Comunista, Universidad Autónoma Metropolitana, México. 
Negri, Antonio, 2003, "N for Negri: Antonio Negri in Conversation with Carles Guerra”, Grey Room, núm. 11, primavera, pp. 86-109.

Murray, Patrick, 2004, "The Social and Material Transformation of Production by Capital: Formal and Real Subsumption in Capital, Volume I", en The Constitution of Capital Essays on Volume I of Marx's Capital, Palgrave Macmillan, Basingstoke / Nueva York, pp. 243-273. 